\title{
MAPK-dependent JA and SA signalling in Nicotiana attenuata affects plant growth and fitness during competition with conspecifics
}

\author{
Stefan Meldau ${ }^{1 *+}$, Lynn Ullman-Zeunert ${ }^{1 \dagger}$, Geetha Govind ${ }^{1,2}$, Stefan Bartram³ and lan T Baldwin ${ }^{1 *}$
}

\begin{abstract}
Background: Induced defense responses to herbivores are generally believed to have evolved as cost-saving strategies that defer the fitness costs of defense metabolism until these defenses are needed. The fitness costs of jasmonate (JA)-mediated defenses have been well documented. Those of the early signaling units mediating induced resistance to herbivores have yet to be examined. Early signaling components that mediate herbivore-induced defense responses in Nicotiana attenuata, have been well characterized and here we examine their growth and fitness costs during competition with conspecifics. Two mitogen-activated protein kinases (MAPKs), salicylic acid (SA)-induced protein kinase (SIPK) and wound-induced protein kinase (WIPK) are rapidly activated after perception of herbivory and both kinases regulate herbivory-induced JA levels and JA-mediated defense metabolite accumulations. Since JA-induced defenses result in resource-based trade-offs that compromise plant productivity, we evaluated if silencing SIPK (irSIPK) and WIPK (irWIPK) benefits the growth and fitness of plants competiting with wild type (WT) plants, as has been shown for plants silenced in JA-signaling by the reduction of Lipoxygenase 3 (LOX3) levels.
\end{abstract}

Results: As expected, irWIPK and LOX3-silenced plants out-performed their competing WT plants. Surprisingly, irSIPK plants, which have the largest reductions in JA signaling, did not. Phytohormone profiling of leaves revealed that irSIPK plants accumulated higher levels of SA compared to WT. To test the hypothesis that these high levels of SA, and their presumed associated fitness costs of pathogen associated defenses in irSIPK plants had nullified the JA-deficiency-mediated growth benefits in these plants, we genetically reduced SA levels in irSIPK plants. Reducing SA levels partially recovered the biomass and fitness deficits of irSIPK plants. We also evaluated whether the increased fitness of plants with reduced SA or JA levels resulted from increased nitrogen or $\mathrm{CO}_{2}$ assimilation rates, and found no evidence that greater intake of these fitness-limiting resources were responsible.

Conclusions: Signaling mediated by WIPK, but not SIPK, is associated with large fitness costs in competing $N$. attenuata plants, demonstrating the contrasting roles that these two MAPKs play in regulating the plants' growth-defense balance. We discuss the role of SIPK as an important regulator of plant fitness, possibly by modulating SA-JA crosstalk as mediated through ethylene signaling.

Keywords: Fitness costs, Induced defense, MAPK, Herbivory, Nicotiana attenuata, Salicylic acid, Jasmonic acid, Ethylene, Nitrogen, Photosynthesis

\footnotetext{
* Correspondence: smeldau@ice.mpg.de; baldwin@ice.mpg.de

${ }^{\dagger}$ Equal contributors

'Department of Molecular Ecology, Max Planck Institute for Chemical

Ecology, Hans-Knöll-Str.8, Jena D-07745, Germany

Full list of author information is available at the end of the article
} 


\section{Background}

Plants have evolved effective defense strategies to ward off natural enemies, including pathogens and herbivores. Allocation of fitness-limiting resources to anti-pathogen and anti-herbivore resistance frequently imposes costs on plants, which are readily seen as reductions in plant growth and fitness. These fitness costs of defense production play a fundamental role in most plant defense theories (reviewed in [1]). Instead of producing costly defense metabolites permanently, plants often activate defense pathways only in response to signals that implicate the presence of attackers. Such plastic defense pathways, so called induced defenses, are generally believed to have evolved as a resource-saving strategy (reviewed in $[2])$.

Fitness costs of induced resistance pathways are frequently evaluated by manipulating defense hormone levels, such as jasmonic acid (JA) and salicylic acid (SA), two hormones which respectively regulate major antiherbivore and anti-pathogen defense responses (reviewed in [2-4]). SA mediates plant resistance to biotrophic, hemibiotrophic pathogens and some piercing/sucking herbivores [5]. Priming of SA-related defense responses increases disease resistance and plant fitness in the field [6]. However, under pathogen-free conditions, maintaining the SA-pathway imposes a trade-off for plant growth and fitness when compared to plants with genetically reduced SA levels [7].

The jasmonate signaling cascade, including the wound hormone JA-isoleucine (JA-Ile), is widely considered to be a master regulator of plant resistance to arthropod herbivores as well as various pathogens (reviewed in [8]). Fitness costs imposed by the activation of JA-mediated defense pathways have been measured by treating plants with JA or by using plants altered in JA production or perception. Application of JA and SA reduces seed production and mutants with reduced sensitivity to these hormones tend to have higher fitness correlates in Arabidopsis thaliana grown under controlled conditions in a glasshouse experiment [9]. When native populations of Coyote tobacco (Nicotiana attenuata) plants were treated with JA, the JA-mediated resistance traits proved to be costly for seed production in the absence of herbivore attack, but benefited plant fitness when plants were attacked by herbivores [10].

Upon herbivore or pathogen attack, endogenous SA and JA levels are strongly regulated by upstream signaling units that mediate defense responses to various attackers. To understand if the ability to be inducible per se can result in fitness costs, we need to analyze the trade-offs in biomass and fitness correlates associated with the signaling units upstream of these phytohormone pathways. Following this approach, in A. thaliana, a single $R$ gene (RPM1), which is involved in bacterial pathogen recognition, was demonstrated to result in large fitness costs to plants grown in the field [11]. Similarly, it was shown that natural variation at a single genomic locus, involved in regulating SA and JA levels, can explain growth and resistance phenotypes of a large number of A. thaliana accessions [12]. Therefore, analyzing costs of such upstream regulators can help explain growth and defense polymorphism in natural populations. While these studies describe costs of $R$ genes involved in resistance to pathogens, the costs of perception and signaling units mediating resistance to herbivores upstream of hormonal sectors remain unexplored.

In $N$. attenuata, one of its main natural defoliators, the lepidopteran larvae Manduca sexta, is perceived through fatty acid-amino acid conjugates (FACs) present in the insect's oral secretions (reviewed in [13]). It was reported recently that FAC perception results in growth reductions in $N$. attenuata [14], but the underlying mechanisms remain elusive. One of the earliest molecular events in FAC perception is the activation of mitogen-activated protein kinases (MAPK, [15]). MAPK activity is important for the induction of plant defense responses upon herbivore attack, including the regulation of various hormonal pathways (Figure 1). In $N$. attenuata, salicylic acid-induced protein kinase (SIPK) and wound-induced protein kinase (WIPK), as well as their homologues in tomato (Lycopersicum esculentum), cultivated tobacco (N. tabacum) and A. thaliana mediate the activation of defense-related hormonal responses in herbivory-induced tissues [15-18]. Both, SIPK and WIPK, regulate wound and herbivory-induced JA and JA-Ile levels, whereas only SIPK regulates herbivoryinduced ethylene (ET) levels in N. attenuata [15]. LecRK1, which is an important negative regulator of herbivory-induced SA levels is also regulated by SIPK and WIPK ([19]; Figure 1).

$N$. attenuata is an annual plant that grows in the immediate post-fire environment in the Great Basin Desert (Utah, USA) where it occurs in monoculture-like populations, surrounded by conspecific competitors. Because this environment is characterized by highly reduced nitrogen availability, synchronized seed germination and intense intra-specific competition, it represents the primordial agricultural niche. In such transiently resourcerich environments, plants are strongly selected for competitive abilities which depend on maximizing the acquisition and the efficient use of acquired resources. In other words, plants are selected to maximize, and not to optimize, resource acquisition. In this manuscript, we analyzed the costs of maintaining and activating herbivoryinduced signaling pathways when plants are grown under the intense resource competition conditions that the plants commonly germinate into in nature, using SIPK and WIPK-silenced $N$. attenuata plants. 


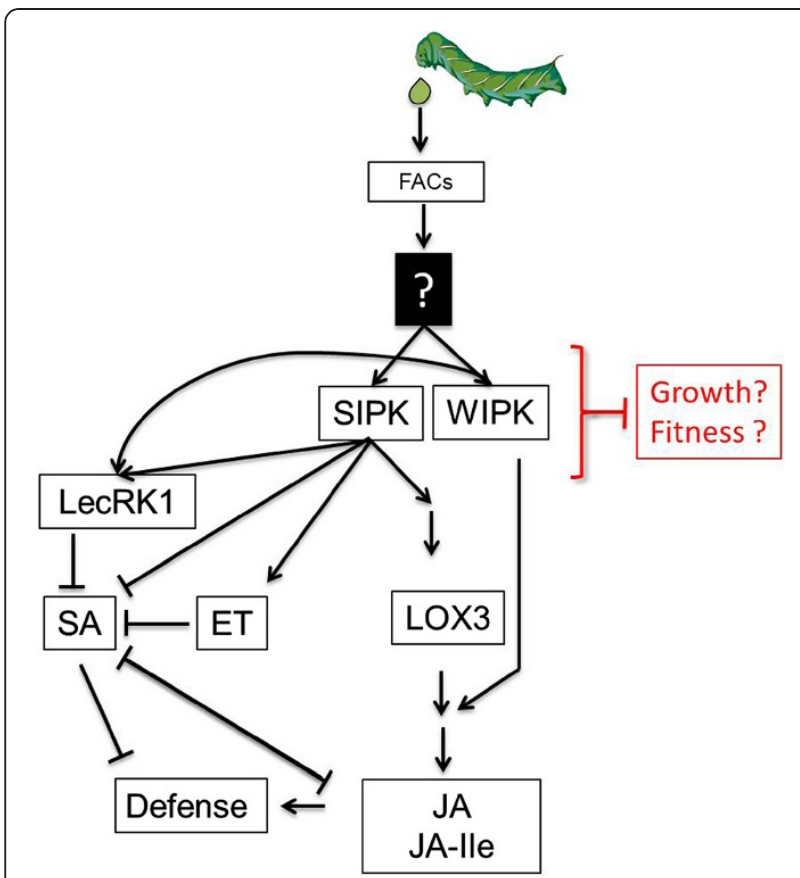

Figure 1 Herbivory-induced signaling in $\mathbf{N}$. attenuata. Oral secretions of Manduca sexta contain fatty acid-amino acid conjugates (FACs), which are perceived by Nicotiana attenuata through an unknown perception event (black filled box with question mark), leading to the activation of salicylic acid-induced protein kinase (SIPK) and wound-induced protein kinase (WIPK). SIPK and WIPK regulate transcripts of LecRK1, which is a negative regulator of SA. SIPK and WIPK regulate biosynthesis of jasmonic acid (JA) and its isoleucine conjugate (JA-lle). SIPK, but not WIPK, also regulates ethylene (ET) emissions, possibly leading to suppressed SA levels, thereby allowing unfettered JA/JA-llemediated defense responses. Growth and fitness consequences of SIPK and WIPK-regulated signaling are unknown (red box).

We grew plants transformed with inverted repeat (ir) constructs for SIPK (irSIPK) and WIPK (irWIPK) in competition with wild type (WT) plants and analyzed plant growth and fitness parameters, with and without simulated herbivory. Quantifying true plant fitness requires the measurements of reproductive success over multiple generations and is therefore difficult to assess. Here we measured flower and seed capsules numbers of plants competing with each other as parameters to assess the fitness consequences of defense signaling pathways. Our data reveal that although both MAPKsilenced lines accumulated less JA after herbivory, only irWIPK plants benefited from the reduced defensive state with higher biomass and fitness. IrSIPK plants accumulated higher levels of SA and when these plants were crossed with oeNahG plants that overexpress bacterial salicylate hydroxylase (NahG), to lower free SA levels, we could partially recover growth and fitness parameters caused by SIPK silencing. Although both kinases are frequently reported to regulate common defense pathways, our data demonstrate that SIPK and WIPK regulate different signaling systems that regulate $N$. attenuata's physiological reconfiguration after herbivore attack and its resulting fitness parameters.

\section{Results}

Silencing two herbivory-responsive MAPKs differentially affects plant growth under field and glasshouse

\section{conditions}

Two mitogen-activated protein kinases, SIPK and WIPK, in $N$. attenuata have been shown to regulate herbivoryinduced defense responses [20]. As defenses are costly and thought to incur trade-offs for plant growth and reproduction [1], we evaluated if silencing SIPK and WIPK benefited plant growth and fitness. Growth was first analysed in transgenic irSIPK and irWIPK plants in a paired design with WT in their natural habitat in the Great Desert Basin in Utah, USA. Although both transgenic plants have similar reductions in their direct and indirect defenses in comparison to WT plants [20], surprisingly, irSIPK plants were significantly smaller than WT (Figure 2A, Welch two sample $t$-test, $\mathrm{p}=0.049$ ), whereas irWIPK plants grew similarly to competing WT plants (Welch two sample $t$-test, $\mathrm{p}$-value $=0.17$; Figure 2A). A table with all additional statistical values is provided in the supplemental material (Additional file 1: Table S1).

A similar experiment was carried out in the glasshouse under controlled conditions. Defense-related trade-offs in $N$. attenuata were only found when plants were growing in competition with conspecifics [2]. Thus, we used a paired design of size-matched plants competing for the same resources in individual pots to analyze plant growth and fitness. As MAPK activity and JA-levels are highly induced during herbivore attack [15], we assumed that differences in growth and fitness would be more pronounced when the competing plants were elicited by a simulated herbivory treatment (wouding and application of $M$. sexta oral secretions, W + OS, see Methods). In addition to irSIPK and irWIPK, we used JA deficient plants (asLOX3) [20,21] with lower levels of antiherbivory defense metabolites as "positive controls" as these plants should perform better in comparison to competing WT plants. The results of the glasshouse experiments were comparable with the results from the field. Independent of treatment, irSIPK plants were smaller than WT and produced fewer capsules (Figure 2B), whereas irWIPK plants and asLOX3 plants produced significantly more dry mass and greater capsule numbers after treatments (Figure 2B). Although MAPK activity and JA levels are highly induced by $\mathrm{W}+$ OS treatments, the growth benefits in WIPK and $L O X 3$-silenced plants were also observed in the absence of $\mathrm{W}+\mathrm{OS}$ treatments, which suggests that plants are 

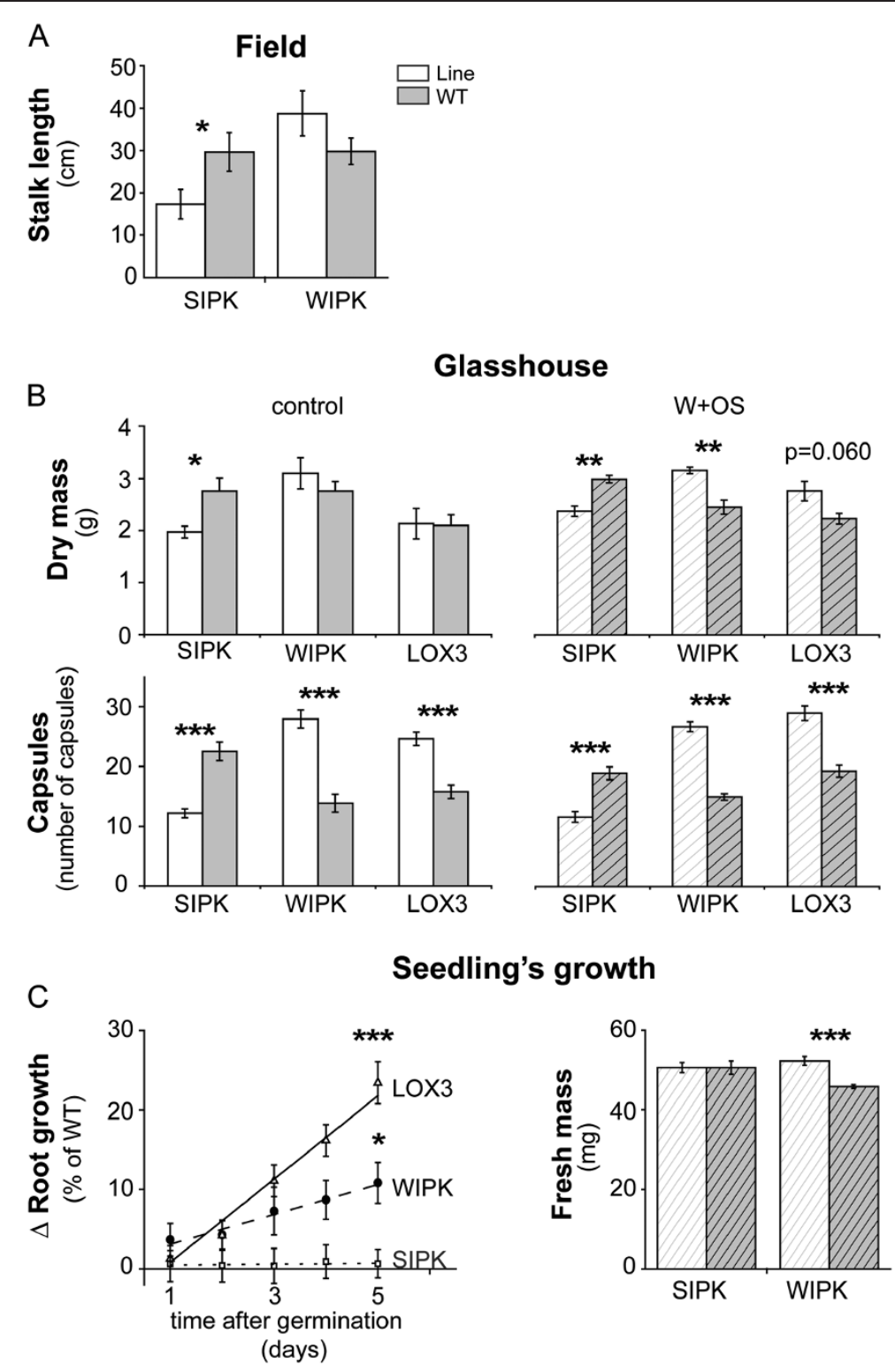

Seedling's growth

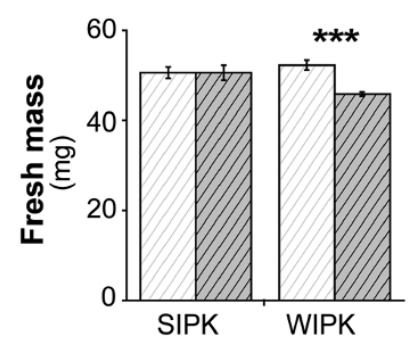

Figure 2 Growth and fitness of $\boldsymbol{N}$. attenuata plants impaired in herbivory-induced defense signaling. (A) Mean $( \pm S E, n \geq 9)$ stalk length of irSIPK and irWIPK plants grown for 44 days in the plant's natural habitat (Utah, USA) compared to size-matched wild type (WT) plants. (B) Mean ( \pm SE) dry mass ( $n \geq 3$, pooled samples, each containing 5 biological replicates) and total capsule number ( $n \geq 19)$ of transgenic plants (irSIPK, irWIPK) grown in competition with wild type (WT) plants. To simulate herbivory, three rosette leaves of each plant were wounded with a pattern wheel (W) and treated with $10 \mu \mathrm{L}$ 1:5 diluted Manduca sexta oral secretions (OS). Untreated plants served as controls. (C) Mean ( \pm SE, $n \geq 16$.) relative root growth difference to WT in wounded seedlings grown in competition (asteriks indicate significant differences between irLOX3 and irWIPK when compared to irSIPK plants (ANCOVA, $\left.F_{2,344}=13.46, p<0.001\right)$ ) and mean $( \pm S E, n=8)$ seedling fresh mass grown under low nutrient conditions. Asteriks indicate significant differences between a transgenic line and WT in one pot (Welch two sample T-test; ${ }^{* * *} p<0.001$; **: $p<0.01 ; *$ : $p<0.05)$.

continuously challened by various environmental stresses that activate JA signaling (Figure 2B).

In $N$. attenuata, simulated herbivory can already inhibit growth of seedlings [14]. To assess growth effects of SIPK and WIPK-silenced plants at the seedling stage, we performed an in vitro seedling competition assay (Additional file 2: Figure S1). Under untreated conditions, we did not find growth difference of seedlings (data not shown), whereas wound-induced WIPK (ANCOVA, $\left.\mathrm{F}_{5,344}=20.79, \mathrm{p}=0.049\right)$ and LOX3 (ANCOVA, $\mathrm{F}_{5,344}=$ $\left.20.79, \mathrm{p}=3.72 \mathrm{e}^{-07}\right)$ grew faster than WT, while SIPKsilenced seedlings grew similarly (ANCOVA, $F_{5,344}=$ $20.79 \mathrm{p}=0.95$; Figure 2C). The biomass accumulation of WIPK- and SIPK-silenced seedlings reflected the trend 
found in the seedling root growth assay (Welch two sample $t$-test, $\mathrm{p}=3.3 \mathrm{e}-04$; Figure $2 \mathrm{C}$ ). In summary, our data from three different growth assays demonstrated that silencing WIPK benefits plant growth and fitness, but that irSIPK plants did not benefit from their JA deficiency.

\section{IrSIPK plants accumulate more SA in leaf tissues}

$\mathrm{SA}$ is known to negatively influence plant growth and development [22]. A previous study demonstrated that leaves of irSIPK plants grown in individual pots have higher basal SA-levels than do WT plants (see Supplemental Figure 4 in [23],). To test, if SIPK, WIPK or $L O X 3$-silenced plants also have altered SA-levels when grown in experimental designs that included an intraspecific competitor, SA-levels were measured in untreated leaf tissues and $1 \mathrm{~h}$ after $\mathrm{W}+\mathrm{OS}$ treatments. We found significantly higher SA-levels for irSIPK plants independent of treatment (Welch two sample $t$-test, control: $\mathrm{p}=0.002 ; \mathrm{W}+\mathrm{OS}: \mathrm{p}=0.048$ ) (Figure 3A). Of the other transgenic lines tested, only irWIPK plants accumulated slightly less SA after $\mathrm{W}+\mathrm{OS}$ treatments when compared to competing WT plants (Welch two sample $t$-test, $\mathrm{p}=0.037$ ). However, JA-levels of irSIPK, ir WIPK and irLOX3 lines were greatly reduced after $\mathrm{W}+\mathrm{OS}$ treatments compared to the corresponding WT (Figure 3B). We thus hypothesized that higher SA-levels may influence the growth and fitness phenotype of these JA-deficient plants. To test this hypothesis, irSIPK plants were crossed with an overexpression (oe) salicylic acid hydroxylase (NahG) line (oeNahG; [24]). The crossed line, $S x N$, had SA-levels similar to WT (Figure 3A) and lower JA-levels when compared to the corresponding WT plants (Welch two sample T-test, $\mathrm{p}=0.004 ;$ Figure 3B). Notably, JA levels were also reduced in oeNahG, when compared to the corresponding WT plants (Figure 3B). A previous report showed that oeNahG plants grown in single pots did not show any difference in JA levels $1 \mathrm{~h}$ after $\mathrm{W}+\mathrm{OS}$ treatments [19] and we hypothesize that different growth conditions in our competition setup might have caused the altered accumulation of JA in the oeNahG line.

\section{Reducing SA levels in irSIPK plants partially restores the JA deficiency-mediated growth promotion found in JA-deficient plants}

To investigate the influence of SA on irSIPK's growth and reproduction, additional competition experiments including $S x N$ and oeNahG plants were carried out. To combine the results of several experiments in a single graph, we calculated the relative differences between the two competing plants in one pot and expressed them relative to the WT plants used in the individual experiments (Figure 4A). Crossing irSIPK with oeNahG resulted in a phenotype similar to plants deficient in JA and JA-mediated defenses (irWIPK and irLOX3). SxN plants had greater biomass (ANOVA, $\mathrm{F}_{2,97}=11.12$, $\mathrm{p}=4.5 \mathrm{e}^{-05}$; Figure $4 \mathrm{~B}$ ), a higher capsule count (ANOVA; Line: $F_{1,58}=21.18, p=2.32 \mathrm{e}^{-05}$; Treatment: $F_{1,58}=8.08$, $\mathrm{p}=0.006$; Figure $4 \mathrm{C}$ ) and higher number of flowers (ANOVA; Line: $\mathrm{F}_{1,58}=45.90, \mathrm{p}=7 \mathrm{e}^{-09}$; Figure 4D) than their corresponding WT, whereas irSIPK plants did not, indicating that higher SA levels are fitness-limiting factors in irSIPK plants. Since $S x N$ accumulates less JA than oeNahG plants, we speculated that the cross would realize greater fitness benefits than the oeNahG plants. However, independent of treatment, $S x N$ had a similar increase in growth and fitness when compared to their corresponding WT, as did oeNahG plants (Figure 4), indicating that silencing SIPK impairs growth and fitness in $N$. attenuata also via SA-independent pathways and that SIPK-silencing does not effect the oeNahG-mediated growth and fitness promotion.

In comparison to the data presented in Figure 2B, where ir WIPK plants accumulated significantly more biomass when plants were treated with $\mathrm{W}+\mathrm{OS}$, the experiments presented in Figure 4 revealed a constitutively higher biomass in ir WIPK plants, when compared to WT plants. In addition, the reduced biomass and seed capsule number is also less pronounced for irSIPK plants, when data from both experiments are compared. These effects could be due to slightly different soil conditions between the two experimental set-ups (see Methods).

\section{Differences in photosynthetic rates do not explain growth and fitness differences of irSIPK, irWIPK and irLOX3 plants}

Silencing of ribulose-1,5-bisphosphate carboxylase/oxygenase (RuBisCO) in $N$. attenuata leads to a decrease in photosynthetic rate and reduced plant growth and lower amounts of defense metabolites after treatment with simulated herbivory [25]. Photosynthetic rates are also influenced by herbivory [26], biotic stress [27] and plant hormone levels. In particular exogenous SA application was shown to reduce photosynthetic activity by altering chloroplast structure [28], RuBisCO activity [29] and transcript levels of photosynthetic genes [30]. Thus, we hypothesized, that irSIPK plants would show reduced growth and fitness compared to irWIPK, irLOX3 and WT plants as a result of lower photosynthetic rates mediated presumably by its higher SA levels. However, irSIPK plants had a similar or even higher photosynthetic rates than WT and the other transgenic plants (ANOVA, $\mathrm{F}_{2,56}=15.7, \mathrm{p}=3.9 \mathrm{e}^{-06}$ ) (Figure 5). Consistent with these results, reduced $\mathrm{SA}$ levels in $S x N$ plants also did not result in increased photosynthetic rates compared to irSIPK plants. These data indicate that 1) photosynthetic rates under these growth conditions are independent of SA levels and 2) lower amounts of 


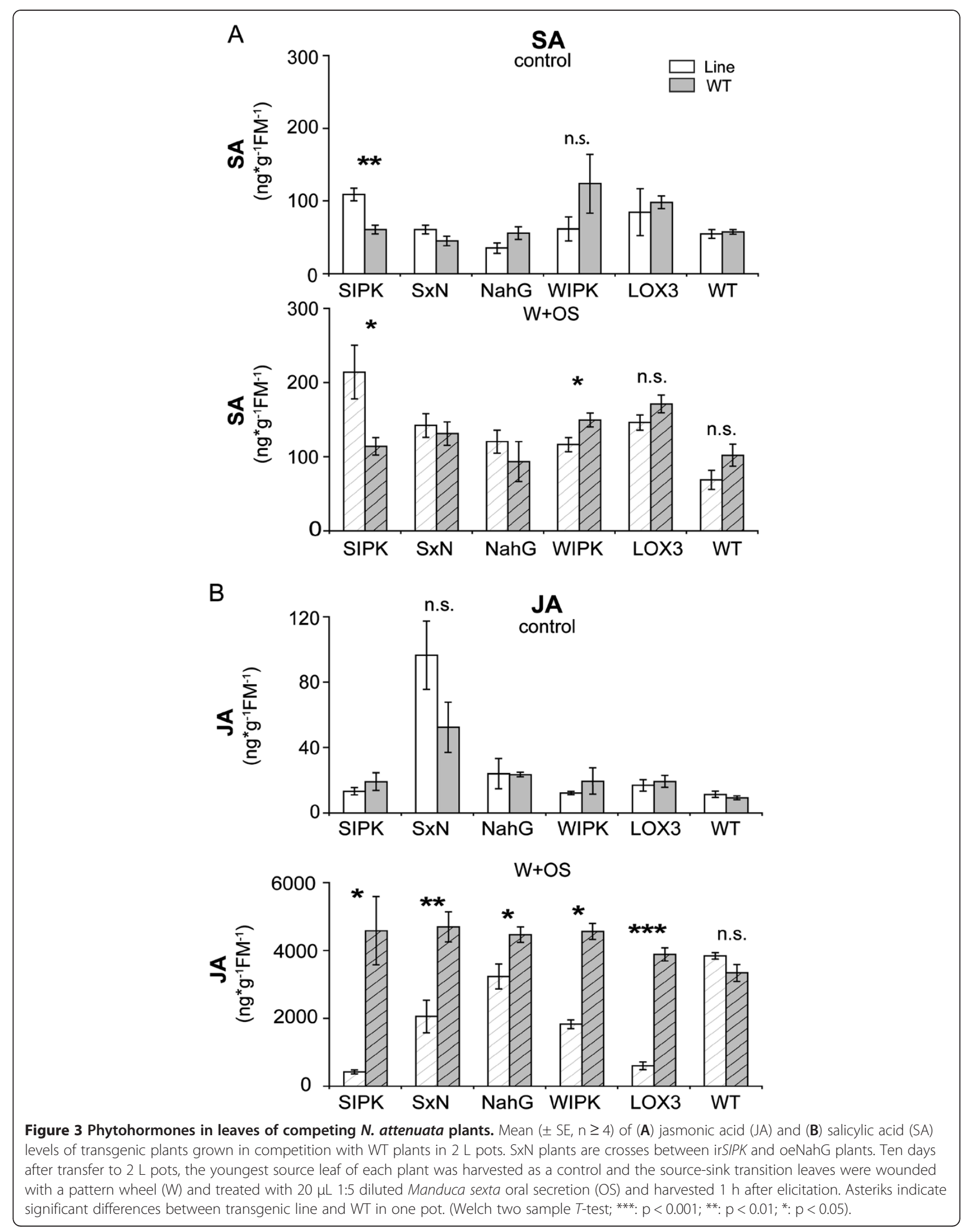




\section{A}

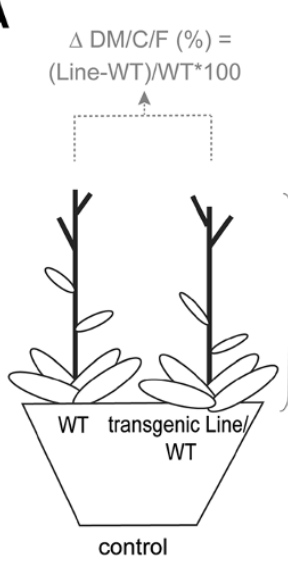

$\Delta \mathrm{DM} / \mathrm{C} / \mathrm{F}(\%)=$
$($ Line-WT $) / \mathrm{WT}^{*} 100$

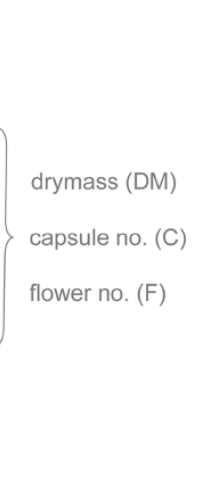

in

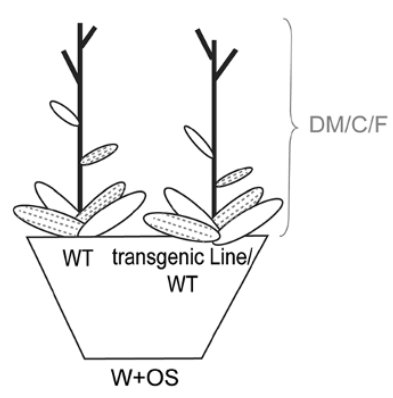

B

Dry mass
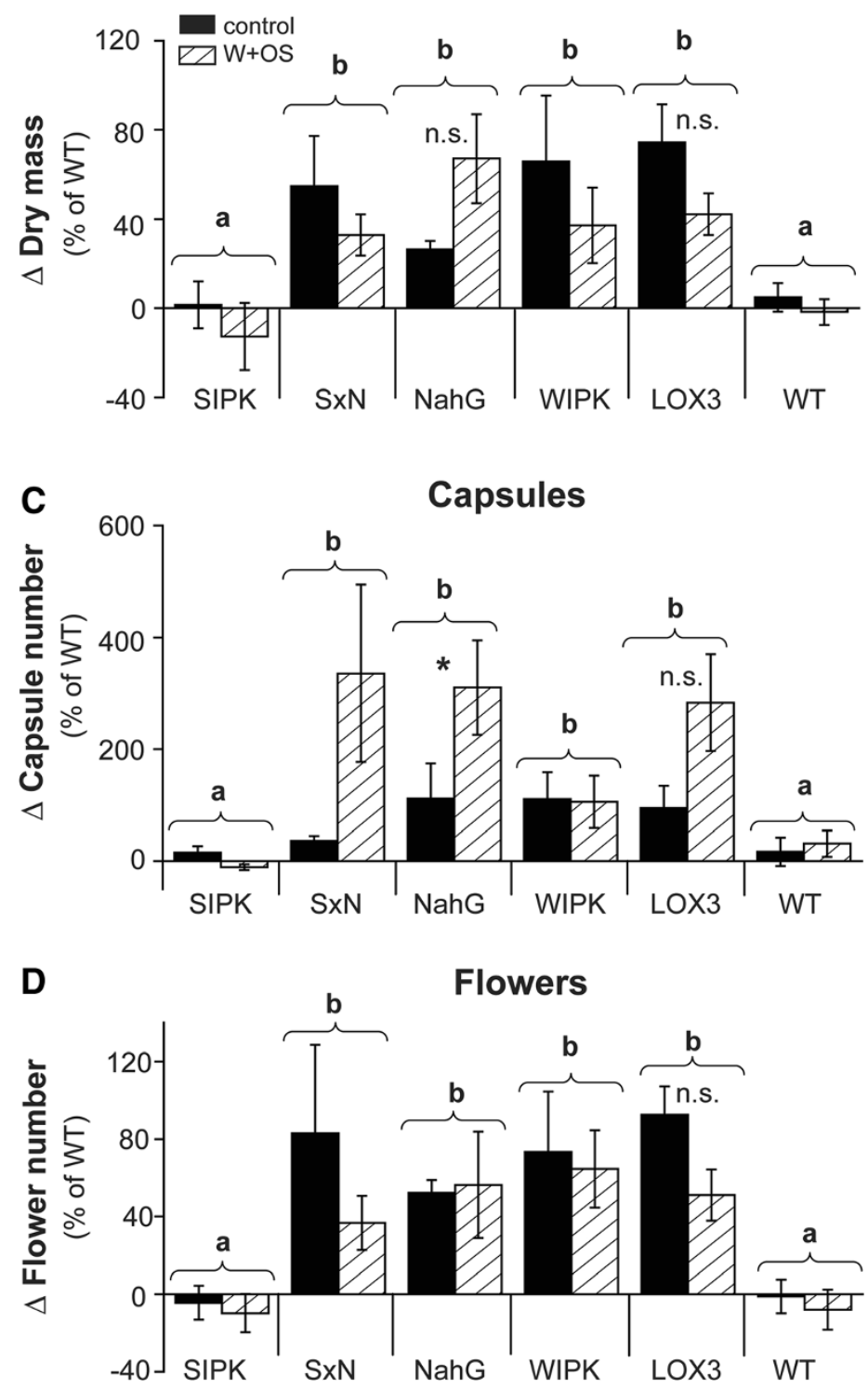

Figure 4 (See legend on next page.) 
(See figure on previous page.)

Figure 4 Reducing SA levels in SIPK-silenced plants restores growth. (A) Scheme of the exerimental approach. The transgenic lines (respectively WT plants) were grown with size matched WT plants in competition in one pot. One half of the plants was wounded with a pattern wheel and treated with Manduca sexta's oral secretion (W + OS), the other half was kept as untreated controls. During the experiment, drymass $(" \mathrm{DM}$ "), capsule (" $\mathrm{C}$ ") and flower ("F") number were determined. For comparison between treatments, the difference between the two plants (LineWT) in one pot was calculated for each treatment and expressed in \% of the individual WT of that specific pot (see formula in graphic). Differences in (B) dry mass, (C) capsule number and (D) flower number of transgenic lines (irSIPK, irWIPK, irLOX3, oeNahG, SXN) compared to competing wild type (WT) plants. Ten days after transfer to $2 \mathrm{~L}$ pots, rosette leaves of transgenic and WT plants were wounded with a pattern wheel (W) and treated with $10 \mu \mathrm{L}$ 1:5 diluted Manduca sexta oral secretion (OS). Treatment was repeated for two consecutive days. At the stalk elongation stage, W + OS treatment was repeated with expanded S1 leaves. Non-elicited plants were used as controls. The minimum adequate model is represented through small letters (a, b; ANOVA, dry mass: Line: $F_{2,97}=11.12, p<0.001$, capsule number: Line: $F_{1,58}=21.18, p<0.001$, Treatment: $F_{1,58}=8.08, p<0.01$; flower number: Line $F_{1,58}=45.90, p<0.001$ ). Asterics indicate significant differences between control and $W+O S$ treatment (Welch two sample t-test, *: $\mathrm{P}<0.05$, n.S. $=$ no significant difference).

photosynthetic products cannot explain why irSIPK plants did not benefit from reduced JA-mediated defenses.

JA has been shown to down-regulate photosynthesisrelated gene expression [21]. Therefore, higher photosynthetic activity might support the growth and fitness of WIPK and LOX3 silenced plants. But irWIPK and $\operatorname{ir} L O X 3$ plants - though they had similar reductions in JA levels compared to WT (Figure 3B) - showed the opposite patterns of photosynthetic rates (Figure 5), and even had a lower photosynthetic activity compared to WT. Therefore, we conclude that the growth promotion of irWIPK and irLOX3 plants is not mediated by improved $\mathrm{CO}_{2}$ assimilation.

Leaf JA and SA-levels do not influence competitive ability for nitrogen acquisition

In addition to photosynthetic rates, the availability of nitrogen influences growth and defense of plants. Under low nitrogen regimes, $N$. attenuata plants grew slower and had lower levels of nitrogen-intensive defense compounds than plants grown under high nitrogen levels [31]. Furthermore, when grown in competition, plants impaired in the production of trypsin proteinase inhibitors (TPIs), a
JA-induced nitrogen-intensive defense, produced more seed capsules and were taller than their neighbouring WT plants [32]. Based on these results, irSIPK, irWIPK and irLOX3 plants were expected to forgo the costs nitrogen investments in nitrogen-intensive defense metabolites $[20,33]$. Several lines of evidence suggest that JA [34] and SA $[35,36]$ can influence the plant's nitrogen assimilation and metabolism. Based on these findings, we evaluated if the differences in growth of the three transgenic lines compared to WT were due to altered competitive availabilities for nitrogen acquisition. We grew the three transgenic lines and WT in competition pairs and pulselabeled the pots with nitrogen in form of $\mathrm{K}^{15} \mathrm{NO}_{3}$. Although irWIPK and irLOX3 plants showed higher total nitrogen content than WT plants before wounding (ANOVA, $\mathrm{F}_{2,102}=29.25, \mathrm{p}=9.1 \mathrm{e}^{-11}$; Figure 6A), after this treatment they showed a similar nitrogen content as WT. In addition, all transgenic lines incorporated similar amounts of ${ }^{15} \mathrm{~N}$ compared to their corresponding WT plants (ANOVA, $\mathrm{F}_{5,94}=0.98, \mathrm{p}=0.44$; Figure $6 \mathrm{~B}$ ) and only $S x N$ showed a treatment effect (Welch two sample $t$-test, $\mathrm{p}=0.009)$. Moreover, seeds of all transgenic lines had similar total $\mathrm{N}$ and ${ }^{15} \mathrm{~N}$ contents

\section{Photosynthesis}

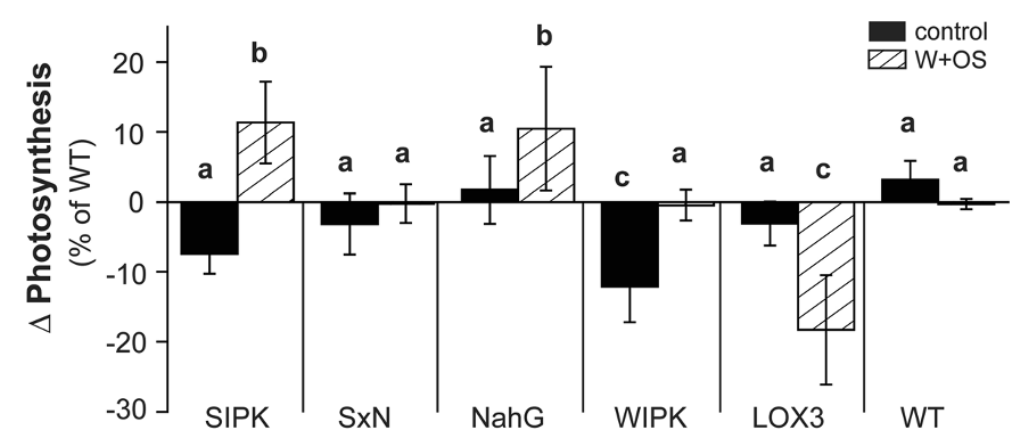

Figure 5 Growth differences of transgenic plants are not correlated with $\mathrm{CO}_{2}$ assimilation rates. Differences $(m e a n \pm S E, n \geq 4)$ in photosynthesis rates between transgenic lines (irSIPK,irWIPK, irLOX3, oeNahG, SXM) compared to competing wild type (WT) plants (calculated as described in Figure 4A). Rosette leaves were OS-elicited as described in Figure 4. Photosynthesis rate was measured at the youngest treated rosette leaf 1 day after the last treatment. The minimum adequate model is represented through small letters $\left(a, b, c ; A N O V A, F_{2,56}=15.70\right.$, $p<0.001)$. 
(Additional file 3: Figure S2). Therefore, we conclude that JA and SA levels in leaves do not correlate with nitrogen uptake and content under these growth conditions. However, we cannot exclude that the growth and fitness phenotype of irWIPK, irLOX3 and irSIPK was influenced by an altered nitrogen allocation towards growth and reproduction, once the nitrogen was incorporated by the plant.

\section{Discussion}

Activation of MAPKs is one of the earliest molecular events in response to herbivore perception [15]. In this study, a reversed genetics approach was used to analyse if maintaining two herbivory-induced MAPKs, namely NaSIPK and NaWIPK, confer fitness costs to a native tobacco species. Our data show that, although silencing these two MAPKs abolished herbivory-induced JA production, which is known to impose fitness costs on plants, only WIPK-silenced plants benefited from these reductions in terms of increased growth and fitness. These results suggest that in addition to JA signaling and JA-associated defenses, SIPK and WIPK regulate different suits of physiological responses after the perception of herbivory, responses that have profound effects on a plant's ability to maximize their fitness. One of these responses is SA signaling.

\section{SIPK and WIPK silencing differentially effects SA levels}

SIPK and WIPK have frequently been shown to regulate similar responses to biotic and abiotic stresses [37]. Both MAPKs redundantly regulate defense responses and wound and herbivory-induced JA/JA-Ile levels in tomato and $N$. attenuata $([15,16] ;[20])$. In $N$. attenuata, both kinases regulate transcript levels of genes important for defense against herbivores [15] including LecRK1, which is crucial for herbivory-induced downregulation of SA [19]. Interestingly, only SIPK-, but not WIPK-, silencing led to elevated SA levels; WIPK even accumulated slightly less SA in leaves after simulated herbivory, suggesting that regulation of LecRK1 transcripts is not responsible for the differential accumulations of SA levels (Figure 3B). Silencing SIPK, but not WIPK, impaires herbivory-induced ET levels in $N$. attenuata. Similarily, only plants deficient in MPK6, the homologue of SIPK in A. thaliana, but not MPK3 (WIPK homologue)-deficient plants show reduced herbivory-induced ET levels $[15,17]$. Diezel and colleagues demonstrated that $N$. attenuata plants impaired in ET biosynthesis or perception accumulated higher levels of herbivory-induced SA; similarily, SA-mediated signaling is suppressed by ET in A. thaliana [38,39]. Collectively, these results suggest that the increased SA levels in SIPK silenced plants are a result of impaired ET signaling. Future experiments designed to recover ET emissions in SIPK silenced plants will help to understand the role of ET in mediating the SA phenotype in irSIPK plants.

\section{Can increased SA mask JA-mediated trade-offs in irSIPK plants?}

JA- and methyl-JA-induced responses were reported to negatively affect growth and fitness in several plant species $[10,40,41]$ and plant productivity was enhanced when JA levels or JA/JA-Ile sensitivity were genetically reduced ([9], [42]). Reducing JA levels also increased plant growth and fitness in WIPK- and LOX3-silenced $N$. attenuata plants (Figures 2 and 4). In contrast, irSIPK plants which showed the highest reductions in herbivory-induced JA levels (Figure 3), did not benefit in terms of growth and fitness. Inhibition of JA-induced defense responses by negative crosstalk through higher SA levels has been intensively studied (reviewed in [43]). In $N$. attenuata, elevated SA levels were found to strongly suppress defense responses to herbivores $[19,38]$. Although oeNahG plants did not show differences in basal SA levels, which is consistant with data presented in [19], the oeNahG plants still produced more biomass and fitness when compared to competing WT plants. It is possible that SA levels in other tissues than leaves might be reduced in oeNahG plants. Future experiments designed to analyze the SA levels in other tissues, such as roots, might shed light on this phenomenon. By crossing irSIPK with oeNahG plants, we tested if higher SA levels could mask the JA deficiency-mediated growth benefits in SIPK silenced plants. Although $S x N$ plants showed similar SA levels when compared to oeNahG, the cross accumulated significantly less JA (Figure 3). However, the elevated biomass and fitness of oeNahG plants was not further increased by JA-deficiency in $S x N$, demonstrating that SA-independent pathways might also be involved in suppressing growth benefits in JA-deficient irSIPK plants. Although we did not observe developmental abnormalities in response to SIPK-silencing, these plants might also have other pleiotropic effects, which may influence plant growth and fitness. For example, it was shown that silencing the NaSIPK-homolog MPK6 in Arabidopsis effects stomata patterning [44-46]. In $N$. attenuata, stomata size and density of irSIPK plants are similar to that of WT plants (data not shown). Future studies designed to identify specific phosphorylation targets regulated by SIPK will help to elucidate its important role in plant growth and fitness regulation.

\section{Mechanisms of JA- and SA-mediated plant growth suppression}

Contrasting effects of SA on photosynthesis have been described [7,29,47-49], whereas JA is thought to affect photosynthesis-related gene expression negatively [21]. 

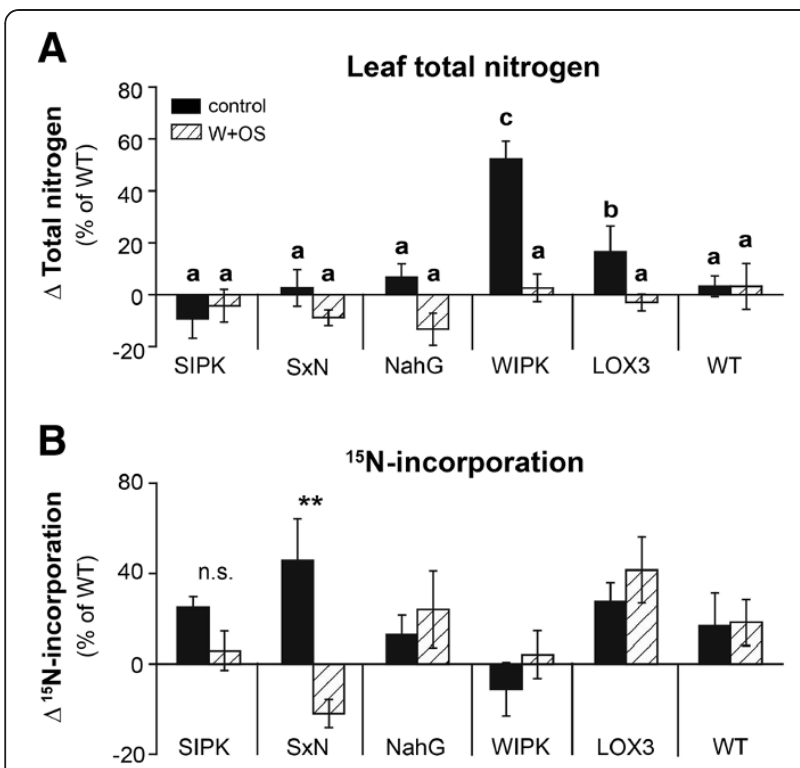

Figure 6 Growth differences in transgenic plants are not correlated with nitrogen uptake. Differences (mean $\pm S E, n \geq 5$ ) in (A) total nitrogen and (B) ${ }^{15} \mathrm{~N}$-incorporation between transgenic lines (irSIPK, irWIPK, irLOX3, oeNahG, SXN) compared to competing wild type (WT) plants (calculated as described in Figure 4A). 7 days after transfer to $2 \mathrm{~L}$ pots, the oldest sink leaf was marked and each plant pair was pulse-labeled with $5.1 \mathrm{mg}$ nitrogen delivered as $\mathrm{K}^{15} \mathrm{NO}_{3}$. Three days later, rosette leaves of transgenic plants and $\mathrm{WT}$ were OS-elicited as described for Figure 4. Leaves were harvested five days after last treatment. Total nitrogen and ${ }^{15} \mathrm{~N}$-incorpration were determined by IRMS (see Methods). The minimum adequate model is represented through small letters ( $a, b, c$; total nitrogen: ANOVA, $F_{2,102}=29.251, p<0.001 i^{15} \mathrm{~N}$-incorporation). Asterics indicate significant differences between control and $\mathrm{W}+\mathrm{OS}$ treatment (Welch two sample t-test, $\mathrm{p}<0.01$, n.s. = no significant difference).

We did not find a clear correlation between SA or JA levels and photosynthetic rates using our set-up (Figure 5). Since our measurements are just spatiotemporal snapshots, we cannot rule out that photosynthesis and SA or JA levels are correlated at other growth stages or in different tissues.

Another important trait for plant growth under resource-limited conditions is the ability to assimilate nitrogen, a trait that was shown to be altered by JAtreatments in competing $N$. sylvestris plants [50]. However, similar to our photosynthesis measurements, we did not find clear patterns of nitrogen uptake that would explain the growth phenotypes of all JA and SA deficient lines (Figure 6, Additional file 3: Figure S2). Our data do not exclude changes in nitrogen metabolism as a growth promoting factor. All transgenic lines with reduced JA-signaling showed lower levels of nitrogen-intensive defense metabolites than did WT $[20,21]$ which may allocate nitrogen resources towards growth and reproduction. Baldwin [51] discussed fitness optimization as a process of resource allocation and demonstrated that the biosynthesis of nicotine, a JA-induced nitrogen-intensive defense metabolite, can slow growth [52]. JA-induced partitioning of newly fixed carbon and nitrogen into additional secondary metabolite pathways was recently described in $N$. tabacum [53,54] which may lead to an additional reallocation of resources. Further experiments with detailed analysis of different nitrogen pools are required to fully understand the role of nitrogen partitioning in mediating growth and fitness of plants with and without JA and SA perturbations.

In addition to the regulation of metabolite fluxes, SA and JA can also affect developmental processes through the regulation of hormonal pathways. SA can regulate growth through modulation of cell expansion, probably via auxin, [55,56] and might regulate the cell cycle through its crosstalk with cytokinin and brassinosteroid pathways [57,58]. JA was also shown to effect plant growth through the regulation of the cell cycle and cell number in Arabidopsis (Zhang et al., [59]). Thus, the alteration of other hormonal pathways might also influence the growth patterns reported here for $N$. attenuata plants with altered MAPK, JA and SA levels .

\section{Costs of inducibility}

We hypothesized that growth and fitness trade-offs imposed by MAPK signaling will only occur when plants were elicited by simulated herbivory since this treatment highly activates SIPK and WIPK. With the exception of SIPK-silenced plants, all other transgenic lines, including LOX3-silenced and oeNahG plants, produced more dry mass and capsules even without simulated herbivory (Figures 2 and 3). These data demonstrate that basal levels of WIPK activity, JA or SA impairs growth and fitness of competing $N$. attenuata plants. In their natural environment, the synchronized germination of $N$. attenuata plants in the first growing season following fires, which in turn results from the detection of smokederived germination cues, leads to high intraspecific competition (Baldwin et al. [60]) and our growth setup was designed to capture this natural environmental stress. However, competition with conspecifics may have induced WIPK activity, JA or SA levels in other tissues than leaves, such as their root systems. Therefore the reduced levels of defense traits in other tissues might have caused increased growth and fitness in the control, unelicted plants. Comparing defense traits in different tissues, such as roots, of $N$. attenuata plants grown in single pots with plants in competition will help to answer these questions.

Several studies have demonstrated that herbivore attack changes a plant's photosynthetic capacity [60-64], and that photosynthetic proteins are commonly downregulated [65]. Our data suggest that the JA and SA 
mediated costs for growth and fitness are independent of photosynthetic regulation, but we cannot exclude that WIPK activity directly influences photosynthetic activity, as our data have shown lower photosynthesis in unelicited irWIPK plants (Figure 6). Furthermore, irSIPK, ir $L O X 3$ and ir WIPK plants showed a treatment effect on their photosynthetic activity (Figure 5). Therefore, LOX3, SIPK and WIPK activities likely play multiple roles in the regulation of herbivory-induced photosynthesis.

In contrast to their photosynthetic rates, control ir WIPK plants as well as $\operatorname{ir} L O X 3$ plants had significantly higher total nitrogen contents in their rosette leaves compared to their corresponding WT plants (Figure 6). These findings indicate, that costs of basal levels of WIPK and LOX3 activity may be amortized by increases in nitrogen resources.

The life history of $N$. attenuata plants may necessitate basic levels of SA, JA and WIPK activity, which come with the cost of reduced growth and capsule production. WIPK and JA-mediated defenses are elicited by attack from the multitude of herbivores that feed on this plant in nature and these defenses use fitness-limiting resources for their production. However, the importance of SA-mediated defense responses in $N$. attenuata are only poorly understood. Our study suggests that maintaining the SA sector must play an important role for fitness of $N$. attenuata not only by moderating JA induced responses, and that SIPK joins two other components shown to suppress SA responses during OS elicitation, response that allow for unfettered JA-mediated defense production: the ethylene burst [38] and LecRK1 [19]. Analyzing the performance of $N$. attenuata plants with different levels of SA under natural conditions are needed to identify the fitness enhancing factors that require the clearly costly SA pathway.

\section{Conclusions}

In this study, we analyzed the fitness consequences of maintaining signaling elements that mediate early herbivory-induced defense responses in native tobacco, Nicotiana attenuata. Our data demonstrate that silencing two herbivory-induced MAPKs, NaSIPK and NaWIPK, strongly diminished JA levels, but only NaWIPK-silenced plants benefited from these reduced defense responses with increased growth and fitness levels during our competition experiments. We demonstrate that irSIPK-plants do not realize the fitness benefits that are commonly enjoyed by JA-deficient plants, partially because $\mathrm{NaSIPK}$-silencing leads to higher levels of SA. Photosynthesis and nitrogen acquisition rates cannot explain the growth differences in our setup, indicating that the observed growth phenotypes are rather mediated by resource allocations or signaling mediated growth reductions. Future experiments are needed to identify the specific metabolic pathways by which SAand JA-signaling divert resources from growth and reproduction. For this analysis identifying the other regulatory targets of SIPK will be essential. Herbivoryinduced MAPK activity and JA signaling was shown to vary in natural accessions of $N$. attenuata [66-68] and the natural variation in the SA pathway is currently being analyzed. Determining the costs of the MAPK, JA and SA-mediated pathways for plant growth and fitness contributes to our understanding of the ecological mechanisms behind the genetic variation in these induced defense signaling systems.

\section{Methods \\ Plant growth conditions Germination}

Wild-type Nicotiana attenuata Torr. Ex. Watson seeds of the $30^{\text {th }}$ (field and first glasshouse experiment, Figure 1 ) and $31^{\text {th }}$ (other experiments) inbred generations of an accession which originated from seeds that were collected at the Desert Inn Ranch in Utah 1988 [52] and seeds of different transgenic lines, were sterilized and germinated on Gamborg's 5 media according to Kruegel et al. [69]. For each of the constructs, several independently transformed, homozygous lines harboring single insertions with similar phenotypes, are available and have been fully characterized. For practical reasons, we only used one of the previously described ransgenic lines. The transformed lines used in this study have been previously characterized in the following publications: irSIPK (A-109) and irWIPK (A-56) were described in [20]; oeNahG (A$481)$ in [24,70] and [19]; asLOX3 (A-300) in [21]; irLOX3 (A-562), in [71]. After using as $L O X 3$ plants in the first experiments, we used newly generated ir $L O X 3$ plants, because of their more pronounced reduction in JA levels (22$50 \%$ reduction of the OS-elicited JA burst in asLOX3 [21], $81-83 \%$ in $\operatorname{ir} L O X 3$ ([71], as compared to WT plants).

\section{Glasshouse}

For glasshouse experiments the plants were transferred to Teku pots ten days after germination. Ten days later the plants were planted into $2 \mathrm{~L}$ competition pots. A transgenic plant was always paired with a WT plant. Pots with two WT plants were used as comparison. Plants were grown at $26-28^{\circ} \mathrm{C}$ under $16 \mathrm{~h}$ of light as described by Kruegel et al. [69]. The glasshouse experiment in 2010 was performed with the following modifications: Frühsdorfer Nullerde was used as substrate with additional $0.5 \mathrm{~g} / \mathrm{L}$ PG Multimix (14, 16 and18 days after transfer to $2 \mathrm{~L}$ pots), $0.85 \mathrm{~g} / \mathrm{L}$ phosphate, $0.05 \mathrm{~g} / \mathrm{L}$ Micromax (Scotts), $0.35 \mathrm{~g} / \mathrm{LMgSO}_{4} 7 \mathrm{H}_{2} \mathrm{O}$ added to the soil. As fertilizer, Peters Allrounder (Scotts) was added (20 g/400 L day7-14, $40 \mathrm{~g} / 400 \mathrm{~L}$ day 14-21, 15-30 g/ $400 \mathrm{~L}$ after day 21) with an additional amount of Borax 
(3 g/400 L day 1-7, 2 g/400 L day 7-14, 1 g/400 L after day 14). To perform the experiments under nitrogenlimiting conditions, external nitrogen supplementations were stopped after plants were transferred to $2 \mathrm{~L}$ pots in all experiments.

\section{Field}

Field experiments were carried out as described by Meldau et al. [20]. In brief: seedlings were transferred into hydrated peat pellets fifteen days after germination. After gradual adaption to the local environmental conditions over 14 days, irSIPK and irWIPK, each paired with one size-matched WT plant, were transplanted into an irrigated field plot at the Lytle Ranch Preserve. The release of transgenic plants was carried out under APHIS notification (06-242-101 n). Growth was measured 30 days after transplantation to the field.

\section{Plant treatment and performance measurements}

Eight days after transfer to $2 \mathrm{~L}$ competition pots, each plant pair was pulse-labelled with $10.2 \mathrm{mg}\left(5.1 \mathrm{mg}{ }^{15} \mathrm{~N}\right.$ and $5.1 \mathrm{mg}{ }^{14} \mathrm{~N}$ ) nitrogen as $\mathrm{KNO}_{3}$ (Chemotrade, Leipzig; Merck). Three days later-giving the plants time to assimilate the labeled nitrogen- the oldest sink leaf, youngest source leaf and transition leaf, were wounded (W) with a pattern wheel and the puncture wounds immediately treated with $10 \mu \mathrm{L} \mathrm{1:5}$ diluted Manduca sexta oral secretion (OS) (W + OS) over 3 consecutive days in order to simulate continuous herbivore feeding damage. This treatment effectively mimics herbivore attack and allows for uniform induction kinetics [72].

The oldest sink leaf at the time of labeling was harvested 8 days after the first treatment, while samples of untreated plants were used as controls. When all plants were elongated and prior to bud formation (6 days after the last treatment), S1 leaves were wounded and treated as described for rosette leaves. The flowers, both open and closed, and capsules were then counted between day 63 and 65 after germination. The plants were harvested 12 days later and oven dried for 3 days to determine the dry mass.

\section{In vitro seedling growth assay}

WT and transgenic lines (irWIPK, irSIPK and irLOX3) of $N$. attenuata used in the glasshouse experiments were used for seedling growth assays. The seeds were sterilized and germinated (Kruegel et al., [69]) on full strength media consisting of $\mathrm{H}_{3} \mathrm{BO}_{3} 10 \mu \mathrm{M}, \mathrm{MnSO}_{4} 0.5 \mu \mathrm{M}$, $\mathrm{ZnSO}_{4} 0.5 \mu \mathrm{M}, \mathrm{CuSO}_{4} 0.1 \mu \mathrm{M}\left(\mathrm{NH}_{4}\right)_{6} \mathrm{Mo}_{7} \mathrm{O}_{24} 0.01 \mu \mathrm{M}$, Fe-EDTA $15 \mu \mathrm{M}, \mathrm{KH}_{2} \mathrm{PO}_{4} 0.5 \mathrm{mM}, \mathrm{MgSO}_{4} 1.2 \mathrm{mM}$, $\mathrm{CaCl}_{2} 2.0 \mathrm{mM}$. Nitrogen was supplied as $\mathrm{KNO}_{3}$ at a concentration of $2 \mathrm{mM}$ nitrogen [73]. The seedlings were transferred to $1 / 4^{\text {th }}$ strength media for competition assay when the root length was approximately $1 \mathrm{~cm}$. Special square petri dishes $(120 \times 120 \times 17 \mathrm{~mm})$ for competition experiment were made by cutting the solidified $1 / 4^{\text {th }}$ strength media into blocks of $1 \mathrm{~cm}$ wide with $0.5 \mathrm{~cm}$ space between blocks; and approximately upper $2 \mathrm{~cm}$ was cut. On each block, wild type seedling was paired with uniform length seedling of either irWIPK or irSIPK or irLOX3 (see also Additional file 2: Figure S1). The shoots were placed in the upper air filled portion of the block. After transfer to blocks, one of the cotyledonary leaves of each seedling was wounded with the tips of bent forceps (making three pin holes). The petri dishes were wrapped with a layer of fabric tape (Micropore $3 \mathrm{M}$ Health Care, Neuss, Germany) to allow for gas exchange and were placed vertically in a growth chamber (Kruegel et al., [69]) to ensure that roots grew to the bottom. The shoots grew in the air filled volume of the upper portion of the blocks. The seedlings were allowed to adjust to the transfer shock for one day after which the growth of roots was monitored on a daily basis. At the end of the 7 day competition experiment, the fresh mass of the roots and shoots of both members of the competing pair was determined: the wild type and its competing transformed line.

\section{Phytohormone analysis}

For phytohormone analysis, plants were grown as described above. The plants were used only for phytohormone analysis and not included into the other analyses. The youngest source leaves were harvested as a control 10 days after transfer to $2 \mathrm{~L}$ competition pots, and then transition leaves were wounded and treated with $20 \mu \mathrm{L}$ 1:5 diluted $M$. sexta oral secretion. The treated leaves were harvested an hour later after removal of the midrib and immediately frozen in liquid nitrogen. After extraction, phytohormones were analysed on an LC-MSMS system (Varian 1200 Triple-Quadrupole-LC-MS system; Varian, Palo Alto, CA, USA according to [17]).

\section{Photosynthesis measurement}

Photosynthesis was measured indirectly by determining $\mathrm{CO}_{2}$ assimilation rates. At least 5 replicates were used to analyze photosynthesis using a LI-COR 6400 portable photosynthesis system (LI-COR Bioscience) with $400 \mu \mathrm{mol} / \mathrm{mol} \mathrm{CO}_{2}$ concentration and light intensity of $1200 \mu \mathrm{mol} / \mathrm{m}^{2} / \mathrm{s}$ for measurements.

\section{Sample preparation for isotope ratio mass spectrometry}

${ }^{15} \mathrm{~N}$-incorporation of seed and leaves was analyzed by an elemental analyzer - continuous flow - isotope ratio mass spectrometry (EA-CF-IRMS). One capsule per plant was harvested 71 days after germination. The capsules were harvested when they showed the first signs of opening. Seeds were dried for 2 weeks at room temperature before measurement. The leaf blades of the 
oldest sink leaf at time point of labeling were harvested 5 days after the last treatment, dried at $60^{\circ} \mathrm{C}$ for $48 \mathrm{~h}$ and homogenized before analysis.

In order to accommodate the high sensitivity of the IRMS, samples were diluted to a final labeling of about 1 atom $\%{ }^{15} \mathrm{~N}$ by adding a standard (acetanilide; alice-1) to the sample. Seeds weighing $0.3 \mathrm{mg} \pm 20 \%$ (approximately two seeds), were placed in $40 \mu \mathrm{L}$ tin capsules together with $0.7819 \mathrm{mg} \pm 20 \%$ of the standard. Roughly $0.1250 \mathrm{mg} \pm 20 \%$ of the homogenized and dried plant material was diluted with $0.8325 \pm 20 \% \mathrm{mg}$ of the standard. The exact sample and dilution masses were determined and used to calculate ${ }^{15} \mathrm{~N}$ abundance. Three technical replicates of each sample were analyzed.

\section{Isotope ratio mass spectrometry analysis}

The tin capsules were sealed and combusted (oxidation at $1020^{\circ} \mathrm{C}$, reduction at $650^{\circ} \mathrm{C}$ in a constant helium stream $\left(80 \mathrm{~mL} \mathrm{~min}{ }^{-1}\right.$ ) quantitatively to $\mathrm{CO}_{2}, \mathrm{~N}_{2}$ and $\mathrm{H}_{2} \mathrm{O}$ in an elemental analyzer (EuroEA CN2 dual, Hekatech, Wegberg, Germany). After passing a $\mathrm{CO}_{2} /$ water trap $\left(\mathrm{NaOH} / \mathrm{MgClO}_{4}\right)$ and a chromatographic $\mathrm{CN}$-column at $85^{\circ} \mathrm{C}$, the remaining $\mathrm{N}_{2}$ was transferred via an open split to a coupled isotope ratio mass spectrometer (IsoPrime, Micromass, Manchester, UK). The laboratory working standard was calibrated using IAEA$\mathrm{N}-1$ reference material with a $\delta^{15} \mathrm{~N}$ value of $+0.43 \%$. A caffeine standard (cafice-1) was analyzed together with the samples as quality analysis reference material for long-term performance monitoring of the entire analytical procedure (for details see Werner et al., [74]).

Isotopic ratios of nitrogen

$$
\mathrm{R}_{15_{\mathrm{N}}}=\frac{\left[{ }^{15} \mathrm{~N}\right]}{\left[{ }^{14} \mathrm{~N}\right]}
$$

are expressed in $\delta$ notation versus the international standard $\mathrm{N}_{2}$ (Air) with ${ }^{15} \mathrm{R}_{\mathrm{std}}=0.0036765$.

$$
\delta^{15} \mathrm{~N}_{\mathrm{sa}}=\left(\frac{{ }^{15} \mathrm{R}_{\mathrm{sa}}-{ }^{15} \mathrm{R}_{\mathrm{std}}}{{ }^{15} \mathrm{R}_{\mathrm{std}}}\right)
$$

Usually given in \%o (per mil)

$$
\delta^{15} \mathrm{~N}_{\mathrm{sa}}(\% \mathrm{o})=\left(\frac{{ }^{15} \mathrm{R}_{\mathrm{sa}}}{{ }^{15} \mathrm{R}_{\mathrm{std}}}-1\right) \cdot 1000
$$

Based on the $\delta$ notation, isotope abundance ${ }^{15} \mathrm{~N}$ (\%) was calculated with 1.6.

$$
{ }^{15} \mathrm{~N}_{\mathrm{sa}}(\% \mathrm{o})=\frac{100}{\left(1 /\left(\frac{\delta \mathrm{N}_{\mathrm{pt}}(\%)}{1000}+\right) \cdot{ }^{15} \mathrm{R}_{\mathrm{std}}\right)+1}
$$

based on the following equations

$$
\begin{aligned}
& { }^{15} \mathrm{~N}_{\mathrm{sa}}(\%)=\frac{{ }^{15} \mathrm{R}_{\mathrm{sa}}}{1+{ }^{15} \mathrm{R}_{\mathrm{sa}}} \cdot 100 \\
& { }^{15} \mathrm{R}_{\mathrm{sa}}=\left(\frac{\delta^{15} \mathrm{~N}_{\mathrm{sa}}(\%)}{1000}+1\right) \cdot{ }^{15} \mathrm{R}_{\mathrm{std}}
\end{aligned}
$$

for labeled plant tissue diluted with acetanilide (alice-1, $\delta$

${ }^{15} \mathrm{~N}_{\text {alice- } 1}=-1.36,10.36 \% \mathrm{~N}$ ) calculations were based on the following relations:

$$
\delta^{15} \mathrm{~N}_{\mathrm{pt}}(\% \mathrm{o})=\frac{\delta^{15} \mathrm{~N}_{\mathrm{sa}}(\% \mathrm{o})-\delta^{15} \mathrm{~N}_{\text {alice-1 }}(\% \mathrm{o}) \cdot x_{\text {alice- }}}{x_{\mathrm{pt}}}
$$

$\mathrm{x}_{\text {alice-1 }}=\frac{\% \mathrm{~N}_{\text {alice- } 1} \cdot \mathrm{m}_{\text {alice- }}}{\text { tot }_{\text {alice- } 1}+\text { tot } \mathrm{N}_{\mathrm{pt}}}$ and $\mathrm{x}_{\mathrm{pt}}=\frac{\% \mathrm{~N}_{\mathrm{pt}} \cdot \mathrm{m}_{\mathrm{pt}}}{\operatorname{tot}_{\text {alice- } 1}+\operatorname{tot}_{\mathrm{pt}}}$

With $\% \mathrm{~N}_{\mathrm{pt}}=\frac{\% \mathrm{~N}_{\mathrm{sa}} \cdot \mathrm{m}_{\mathrm{sa}}-\% \mathrm{~N}_{\mathrm{alice}-1} \cdot \mathrm{m}_{\mathrm{alice}-1}}{\mathrm{~m}_{\mathrm{pt}}}$

With ${ }^{15} \mathrm{~N}(\%)=$ atom percent of ${ }^{15} \mathrm{~N} ; \mathrm{R}_{\mathrm{st}}=$ isotope ratio of standard; alice- $1=$ acetanilid used for dilution; $\mathrm{sa}=$ measured sample; $\mathrm{m}=$ mass; $\% \mathrm{~N}=$ total nitrogen percentage; $\mathrm{pt}=$ plant tissue sample; tot $\mathrm{N}=$ total nitrogen mass

\section{Statistical analysis}

All statistical analyses were performed using the software program R (R Developmental Core [75] and the libraries therein (http://www.r-project.org/). For ANOVA analysis, if the assumption of homoscedasticity of variances was violated or the residuals did not follow a normal distribution, the response variables were transformed prior to the analyses using Box-Cox transformation [76]. The Box-Cox-lambda was estimated using Venables' and Ripley's MASS library for R. All models were simplified to the minimum adequate model using Akike's information criterion [77]. The Welch two sample $T$-test was used, in order to account for heteroscedasticity in some data sets. To facilitate comparisons of all statistical analysis, this test was used in all cases.

\section{Additional files}

Additional file 1: Table S1. Statistical analyses and their $\mathrm{P}$ values. Additional file 2: Figure S1. Representative pictures of the competition setups.

Additional file 3: Figure S2. Nitrogen contents of seeds of competing plants.

Competing interests

The authors declare that they have no competing interests. 


\section{Authors' contributions}

SM and ITB did field experiments; SM and LUZ performed glasshouse experiments; GG and ITB established and GG performed in vitro seedling competition assays; SB, SM and L UZ performed the IRMS measurements; SM and LUZ prepared the manuscript, GG, SB and ITB edited the manuscript; LUZ conducted statistical analyses; SM, LUZ, GG and ITB designed experiments. All authors read and approved the final manuscript.

\section{Acknowledgements}

We thank Shiva Jung Pandey and Willi Brand for technical support; Karin Groten, Matthias Erb, Dorothea Meldau and Michael R. Zeunert for helpful comments on the manuscript, Brigham Young University for use of its awesome field station, the Lytle Ranch Preserve, and the Max Planck Society for funding.

\section{Author details}

${ }^{1}$ Department of Molecular Ecology, Max Planck Institute for Chemical Ecology, Hans-Knöll-Str.8, Jena D-07745, Germany. ${ }^{2}$ Current address: Department of Molecular Genetics, Leibniz Institute of Plant Genetics and Crop Plant Research, Corrensstr.3, Gatersleben D-06466, Germany. ${ }^{3}$ Department of Bioorganic Chemistry, Max Planck Institute for Chemical Ecology, Hans-Knöll-Str.8, Jena D-07745, Germany.

Received: 26 April 2012 Accepted: 21 September 2012 Published: 13 November 2012

\section{References}

1. Herms DA, Mattson WJ: The dilemma of plants: To grow or defend. Qarterly Rev of Biol 1992, 67(3):283-335.

2. Heil M, Baldwin IT: Fitness costs of induced resistance: emerging experimental support for a slippery concept. Trends Plant Sci 2002 7(2):61-67.

3. Boss WF, Sederoff HW, Im YJ, Moran N, Grunden AM, Perera IY: Basal signaling regulates plant growth and development. Plant Physiol 2010, 154:439-443.

4. Glazebrook J: Contrasting mechanisms of defense against biotrophic and necrotrophic pathogens. Annu Rev Phytopathol 2005, 43:205-227.

5. Walling LL: Adaptive Defense Responses to Pathogens and Insects. Adv Bot Res 2009, 51:551-612

6. Traw MB, Kniskern JM, Bergelson J: SAR increases fitness of Arabidopsis thaliana in the presence of natural bacterial pathogens. Evolution international journal of organic evolution 2007, 61:2444-2449.

7. Abreu ME, Munne-Bosch S: Salicylic acid deficiency in NahG transgenic lines and sid 2 mutants increases seed yield in the annual plant Arabidopsis thaliana. J Exp Bot 2009, 60:1261-1271.

8. Howe GA, Jander G: Plant immunity to insect herbivores. Annu Rev Plant Biol 2008, 59:41-66.

9. Cipollini DF: Does competition magnify the fitness costs of induced responses in Arabidopsis thaliana? A manipulative approach. Oecologia 2002, 131:514-520.

10. Baldwin IT: Jasmonate-induced responses are costly but benefit plants under attack in native populations. P Natl Acad Sci USA 1998, 95:8113-8118

11. Tian D, Traw MB, Chen JQ, Kreitman M, Bergelson J: Fitness costs of Rgene-mediated resistance in Arabidopsis thaliana. Nature 2003, 423:74-77.

12. Todesco M, Balasubramanian S, Hu TT, Traw MB, Horton M, Epple P, Kuhns C, Sureshkumar S, Schwartz C, Lanz C, Laitinen RAE, Huang Y, Chory J, Lipka V, Borevitz JO, Dangl JL, Bergelson J, Nordborg M, Weigel D: Natural allelic variation underlying a major fitness trade-off in Arabidopsis thaliana. Nature 2010, 465:632-U129.

13. Bonaventure $G$, van Doorn A, Baldwin IT: Herbivore associated elicitors: FAC signaling and metabolism. Trends Plant Sci 2011, 16:294-299.

14. Hummel GM, Schurr U, Baldwin IT, Walter A: Herbivore-induced jasmonic acid bursts in leaves of Nicotiana attenuata mediate short-term reductions in root growth. Plant Cell Environ 2009, 32:134-143.

15. Wu JQ, Hettenhausen C, Meldau S, Baldwin IT: Herbivory rapidly activates MAPK signaling in attacked and unattacked leaf regions but not between leaves of Nicotiana attenuata. Plant Cell 2007, 19:1096-1122.

16. Kandoth PK, Ranf S, Pancholi SS, Jayanty S, Walla MD, Miller W, Howe GA, Lincoln DE, Stratmann JW: Tomato MAPKs LeMPK1, LeMPK2, and LeMPK3 function in the systemi $n$-mediated defense response against herbivorous insects. P Natl Acad Sci USA 2007, 104:12205-12210.

17. Schäfer M, Fischer C, Meldau S, Seebald E, Oelmuller R, Baldwin IT: Lipase Activity in Insect Oral Secretions Mediates Defense Responses in Arabidopsis. Plant Physiol 2011, 156:1520-1534

18. Seo S, Katou S, Seto H, Gomi K, Ohashi Y: The mitogen-activated protein kinases WIPK and SIPK regulate the levels of jasmonic and salicylic acids in wounded tobacco plants. Plant J 2007, 49:899-909.

19. Gilardoni PA, Hettenhausen C, Baldwin IT, Bonaventure G: Nicotiana attenuata Lectin Receptor Kinase1 suppresses the insect-mediated inhibition of induced defense responses during Manduca sexta herbivory. Plant Cell 2011, 23:3512-3532.

20. Meldau S, Wu JQ, Baldwin IT: Silencing two herbivory-activated MAP kinases, SIPK and WIPK, does not increase Nicotiana attenuata's susceptibility to herbivores in the glasshouse and in nature. New Phytol 2009, 181:161-173.

21. Halitschke R, Baldwin IT: Antisense LOX expression increases herbivore performance by decreasing defense responses and inhibiting growthrelated transcriptional reorganization in Nicotiana attenuata. Plant J 2003, 36:794-807.

22. Vicente MRS, Plasencia J: Salicylic acid beyond defence: its role in plant growth and development. J Exp Bot 2011, 62:3321-3338.

23. Kallenbach M, Alagna F, Baldwin IT, Bonaventure G: Nicotiana attenuato SIPK, WIPK, NPR1, and fatty acid-amino acid conjugates participate in the induction of jasmonic acid biosynthesis by affecting early enzymatic steps in the pathway. (vol 152, pg 96, 2010). Plant Physiol 2010, 152:1760.

24. Hettenhausen C, Baldwin IT, Wu J: Silencing MPK4 in Nicotiana attenuata enhances photosynthesis and seed production but compromises abscisic acid-induced stomatal closure and guard cell-mediated resistance to Pseudomonas syringae pv tomato DC3000. Plant Physiol 2012, 158:759-776.

25. Mitra S, Baldwin IT: Independently silencing two photosynthetic proteins in Nicotiana attenuata has different effects on herbivore resistance. Plant Physiol 2008, 148:1128-1138.

26. Kerchev PI, Fenton B, Foyer $\mathrm{CH}$, Hancock RD: Plant responses to insect herbivory: interactions between photosynthesis, reactive oxygen species and hormonal signalling pathways. Plant Cell Environ 2011, 35(2):441-453.

27. Bilgin DD, Zavala JA, Zhu J, Clough SJ, Ort DR, DeLucia EH: Biotic stress globally downregulates photosynthesis genes. Plant Cell Environ 2010, 33(10):1597-1613.

28. Uzunova AN, Popova LP: Effect of salicylic acid on leaf anatomy and chloroplast ultrastructure of barley plants. Photosynthetica 2000 38:243-250.

29. Pancheva TV, Popova LP: Effect of salicylic acid on the synthesis of ribulose-1,5-bisphosphate carboxylase/oxygenase in barley leaves. J Plant Physiol 1998, 152:381-386.

30. Heidel AJ, Baldwin IT: Microarray analysis of salicylic acid- and jasmonic acid-signalling in responses of Nicotiana attenuata to attack by insects from multiple feeding guilds. Plant Cell Environ 2004, 27(11):1362-1373.

31. Lou YG, Baldwin IT: Nitrogen supply influences herbivore-induced direct and indirect defenses and transcriptional responses to Nicotiana attenuata. Plant Physiol 2004, 135:496-506.

32. Zavala JA, Baldwin IT: Fitness benefits of trypsin proteinase inhibitor expression in Nicotiana attenuata are greater than their costs when plants are attacked. BMC Ecol 2004, 4:11.

33. Halitschke R, Gase K, Hui DQ, Schmidt DD, Baldwin IT: Molecular interactions between the specialist herbivore Manduca sexta (Lepidoptera, Sphingidae) and its natural host Nicotiana attenuata. VI. Microarray analysis reveals that most herbivore-specific transcriptional changes are mediated by fatty acid-amino acid conjugates. Plant Physiol 2003, 131(4):1894-1902.

34. van Dam NM, Baldwin IT: Costs of jasmonate-induced responses in plants competing for limited resources. Ecol Lett 1998, 1:30-33.

35. Nazar R, lqbal N, Syeed S, Khan NA: Salicylic acid alleviates decreases in photosynthesis under salt stress by enhancing nitrogen and sulfur assimilation and antioxidant metabolism differentially in two mungbean cultivars. J Plant Physiol 2011, 168:807-815.

36. Sarangthem K, Singh N: Efficacy of salicylic acid on growth, nitrogen metabolism and flowering of Phaseolus vulgaris. Crop Res 2003, 26(2):355-360. 
37. Tena G, Boudsocq $M$, Sheen J: Protein kinase signaling networks in plant innate immunity. Curr Opin Plant Biol 2011, 14:519-529.

38. Diezel C, von Dahl CC, Gaquerel E, Baldwin IT: Different lepidopteran elicitors account for cross-talk in herbivory-induced phytohormone signaling. Plant Physiol 2009, 150:1576-1586

39. Leon-Reyes A, Spoel SH, De Lange ES, Abe H, Kobayashi M, Tsuda S, Millenaar FF, Welschen RAM, Ritsema T, Pieterse CMJ: Ethylene modulates the role of nonexpressor of pathogenesis-related genes 1 in cross-talk between salicylate and jasmonate signaling. Plant Physiol 2009, 149:1797-1809.

40. Cipollini D: Consequences of the overproduction of methyl jasmonate on seed production, tolerance to defoliation and competitive effect and response of Arabidopsis thaliana. New Phytol 2007, 173:146-153.

41. Redman AM, Cipollini DF, Schultz JC: Fitness costs of jasmonic acidinduced defense in tomato, Lycopersicon esculentum. Oecologia 2001, 126:380-385.

42. Royo J, Leon J, Vancanneyt G, Albar JP, Rosahl S, Ortego F, Castanera P, Sanchez-Serrano JJ: Antisense-mediated depletion of a potato lipoxygenase reduces wound induction of proteinase inhibitors and increases weight gain of insect pests. P Natl Acad Sci USA 1999, 96:1146-1151.

43. Pieterse CMJ, Leon-Reyes A, Van der Ent S, Van Wees SCM: Networking by small-molecule hormones in plant immunity. Nat Chem Biol 2009, 5:308-316.

44. Bush SM, Krysan PJ: Mutational evidence that the Arabidopsis MAP kinase MPK6 is involved in anther, inflorescence, and embryo development. J Exp Bot 2007, 58:2181-2191.

45. Wang H, Ngwenyama N, Liu Y, Walker JC, Zhang S: Stomatal development and patterning are regulated by environmentally responsive mitogenactivated protein kinases in Arabidopsis. Plant Cell 2007, 19:63-73.

46. Wang H, Liu Y, Bruffett K, Lee J, Hause G, Walker JC, Zhang S: Haploinsufficiency of MPK3 in MPK6 mutant background uncovers a novel function of these two MAPKs in Arabidopsis ovule development. Plant Cell 2008, 20:602-613.

47. Fariduddin Q, Hayat S, Ahmad A: Salicylic acid influences net photosynthetic rate, carboxylation efficiency, nitrate reductase activity, and seed yield in Brassica juncea. Photosynthetica 2003, 41:281-284.

48. Pancheva TV, Popova LP, Uzunova AN: Effects of salicylic acid on growth and photosynthesis in barley plants. J Plant Physiol 1996, 149:57-63.

49. Slaymaker DH, Navarre DA, Clark D, del Pozo O, Martin GB, Klessig DF: The tobacco salicylic acid-binding protein 3 (SABP3) is the.chloroplast carbonic anhydrase, which exhibits antioxidant activity and plays a role in the hypersensitive defense response. P Natl Acad Sci USA 2002, 99:11640-11645.

50. Baldwin IT, Hamilton W: Jasmonate-induced responses of Nicotiana sylvestris results in fitness costs due to impaired competitive ability for nitrogen. J Chem Ecol 2000, 26(4):915-952.

51. Baldwin IT: An ecologically motivated analysis of plant-herbivore interactions in native tobacco. Plant Physiol 2001, 127(4):1449-1458.

52. Baldwin IT, Gorham D, Schmelz EA, Lewandowski CA, Lynds GY: Allocation of nitrogen to an inducible defense and seed production in Nicotiana attenuata. Oecologia 1998, 115:541-552.

53. Hanik N, Gomez S, Schueller M, Orians CM, Ferrieri RA: Use of gaseous $13 \mathrm{NH}(3)$ administered to intact leaves of Nicotiana tabacum to study changes in nitrogen utilization during defence induction. Plant Cell Environ 2010, 33:2173-2179.

54. Hanik N, Gomez S, Best M, Schueller M, Orians CM, Ferrieri RA: Partitioning of new carbon as ${ }^{11} \mathrm{C}$ in Nicotiana tabacum reveals insight into methyl jasmonate induced changes in metabolism. J Chem Ecol 2010, 36:1058-1067.

55. Scott IM, Clarke SM, Wood JE, Mur LAJ: Salicylate accumulation inhibits growth at chilling temperature in Arabidopsis. Plant Physiol 2004, 135:1040-1049.

56. Xia JC, Zhao H, Liu WZ, Li LG, He YK: Role of cytokinin and salicylic acid in plant growth at low temperatures. Plant Growth Regul 2009, 57:211-221.

57. Hu YX, Bao F, Li JY: Promotive effect of brassinosteroids on cell division involves a distinct CycD3-induction pathway in Arabidopsis. Plant J 2000, 24:693-701.

58. Riou-Khamlichi C, Huntley R, Jacqmard A, Murray JAH: Cytokinin activation of Arabidopsis cell division through a D-type cyclin. Science 1999, 283:1541-1544.
59. Zhang $Y$, Turner JG: Wound-induced endogenous jasmonates stunt plant growth by inhibiting mitosis. PLoS One 2008, 3(11):e3699. doi:10.1371/ journal.pone.0003699.

60. Baldwin IT, Ohnmeiss TE: Coordination of photosynthetic and alkaloidal responses to damage in uninducible and inducible Nicotiana sylvestris. Ecology 1994, 75(4):1003-1014.

61. Halitschke R, Hamilton JG, Kessler A: Herbivore-specific elicitation of photosynthesis by mirid bug salivary secretions in the wild tobacco Nicotiana attenuata. New Phytol 2011, 191:528-535.

62. Hermsmeier D, Schittko U, Baldwin IT: Molecular interactions between the specialist herbivore Manduca sexta (Lepidoptera, Sphingidae) and its natural host Nicotiana attenuata. I. Large-scale changes in the accumulation of growth- and defense-related plant mRNAs. Plant Physiol 2001, 125:683-700.

63. Kessler A, Baldwin IT: Plant responsens to insect herbivory: the emerging molecular analysis. Annu Rev Plant Biol 2002, 53:299-328.

64. Walling LL: The myriad plant responses to herbivores. Journal of Plant Growth Regul 2000, 19:195-216.

65. Giri AP, Wuensche H, Mitra S, Zavala JA, Muck A, Svatos A, Baldwin IT: Molecular interactions between the specialist herbivore Manduca sexta (Lepidoptera, Sphingidae) and its natural host Nicotiana attenuata VII. Changes in the plant's proteome. Plant Physiol 2006, 142:1621-1641.

66. Kallenbach M, Bonaventure P, Gilardoni P, Wissgott A, Baldwin IT: Empoasca leafhoppers attack wild tobacco plants in a jasmonate-dependent manner and identify jasmonate mutants in natural populations. $P$ Natl Acad Sci USA 2012, 109(24). doi:10.1073/pnas.1200363109.

67. Schuman MC, Heinzel N, Gaquerel E, Svatos A, Baldwin IT: Polymorphism in jasmonate signaling partially accounts for the variety of volatiles produced by Nicotiana attenuata plants in a native population. New Phytol 2009, 183:1134-1148.

68. Wu JQ, Hettenhausen C, Schuman MC, Baldwin IT: A comparison of two Nicotiana attenuata accessions reveals large differences in signaling induced by oral secretions of the specialist herbivore Manduca sexta. Plant Physiol 2008, 146(3):927-939.

69. Krügel T, Lim M, Gase K, Halitschke R, Baldwin IT: Agrobacterium-mediated transformation of Nicotiana attenuata, a model ecological expression system. Chemoecology 2002, 12:177-183.

70. Meldau S, Baldwin IT, Wu JQ: SGT1 regulates wounding- and herbivoryinduced jasmonic acid accumulation and Nicotiana attenuata's resistance to the specialist lepidopteran herbivore Manduca sexta. New Phytol 2011, 189:1143-1156.

71. Allmann S, Halitschke R, Schuurink RC, Baldwin IT: Oxylipin channelling in Nicotiana attenuata: lipoxygenase 2 supplies substrates for green leaf volatile production. Plant Cell Environ 2010, 33:2028-2040.

72. Halitschke R, Schittko U, Pohnert G, Boland W, Baldwin IT: Molecular interactions between the specialist herbivore Manduca sexta (Lepidoptera, Sphingidae) and its natural host Nicotiana attenuata. III. Fatty acid-amino acid conjugates in herbivore oral secretions are necessary and sufficient for herbivore- specific plant responses. Plant Physiol 2001, 125(2):711-717.

73. Matt $P$, Geiger M, Walch-Liu P, Engels C, Krapp A, Stitt M: Elevated carbon dioxide increases nitrate uptake and nitrate reductase activity when tobacco is growing on nitrate, but increases ammonium uptake and inhibits nitrate reductase activity when tobacco is growing on ammonium nitrate. Plant Cell Environ 2001, 24:1119-1137.

74. Werner RA, Brand WA: Referencing strategies and techniques in stable isotope ratio analysis. Rapid Communications in Mass Spectrometry 2001, 15:501-519.

75. Team RDC: R: A language and environment for statistical computing. Vienna: R Foundation for Statistical Computing; 2009

76. Sakia RM: The Box-Cox transformation technique: a review. The Statistician 1992, 41:169-178.

77. Ronchetti E: Robust Model selection in regression. Statistics \& Probability Letters 1985, 3:21-23.

doi:10.1186/1471-2229-12-213

Cite this article as: Meldau et al:: MAPK-dependent JA and SA signalling in Nicotiana attenuata affects plant growth and fitness during competition with conspecifics. BMC Plant Biology 2012 12:213. 